\title{
Spatial scales of temperature and salinity variability estimated from Argo observations
}

\author{
F. Ninove ${ }^{1,2}$, P.-Y. Le Traon ${ }^{1,2}$, E. Remy ${ }^{2}$, and S. Guinehut ${ }^{3}$ \\ ${ }^{1}$ Ifremer, Technopole Brest Iroise, Z.I. de la Pointe du Diable, 29280 Plouzané, France \\ ${ }^{2}$ Mercator Ocean, Parc technologique du Canal, 8-10 rue Hermès, 31520 Ramonville-Saint-Agne, France \\ ${ }^{3}$ CLS, Parc Technologique du Canal, 8-10 rue Hermès, 31520 Ramonville-Saint-Agne, France \\ Correspondence to: P.-Y. Le Traon (pierre.yves.le.traon@ifremer.fr)
}

Received: 19 June 2015 - Published in Ocean Sci. Discuss.: 18 August 2015

Revised: 22 October 2015 - Accepted: 4 November 2015 - Published: 14 January 2016

\begin{abstract}
Argo observations from 2005 to 2013 are used to characterize spatial scales of temperature and salinity variations from the surface down to $1300 \mathrm{~m}$. Simulations are first performed to analyze the sensitivity of results to Argo sampling; they show that several years of Argo observations are required to estimate spatial scales of ocean variability over $20^{\circ} \times 20^{\circ}$ boxes. Spatial scales are then computed over several large-scale areas. Zonal and meridional spatial scales ( $L_{x}$ and $L_{y}$ which are zero crossing of covariance functions) vary as expected with latitudes. Scales are of about $100 \mathrm{~km}$ at high latitudes and more of $700 \mathrm{~km}$ in the Indian and Pacific equatorial-tropical regions. Zonal and meridional scales are similar except in tropical-equatorial regions where zonal scales are much larger (by a factor of 2 to 3 ) than meridional scales. Spatial scales are the largest close to the surface and have a general tendency for temperature to increase in deeper layers. There are significant differences between temperature and salinity scales, in particular, in the deep ocean. Results are consistent with previous studies based on sparse in situ observations or satellite altimetry. They provide, however, for the first time a global description of temperature and salinity scales of variability and a characterization of their variations according to depths.
\end{abstract}

\section{Introduction}

Thanks to outstanding international cooperation, Argo - the global array of profiling floats (Roemmich et al., 2009) reached its initial target of 3000 floats in operation in 2007. Argo floats measure every 10 days temperature and salinity from the surface down to $2000 \mathrm{~m}$ and deliver their data both in real time for operational users and after scientific quality control for climate change research and monitoring. Argo has revolutionized oceanography by providing for the first time a near-real-time global description of the ocean state that is fully complementary to satellite observations. An overview of Argo achievements is given in Freeland et al. (2010). Argo data have been used to better understand global and regional sea level rise and ocean heat content variations (e.g., von Schuckmann and Le Traon, 2011), to analyze largescale ocean circulation and mesoscale variations (e.g., Roemmich et al; 2007; Dong et al., 2014) and large-scale salinity variations related to the global hydrological cycle (Durack and Wijffels, 2010). Argo has strong complementarities with satellite altimetry, and Argo data are now systematically used together with altimeter data for ocean analysis and forecasting (e.g., Guinehut et al., 2012; Le Traon, 2013; Oke et al., 2015).

The availability of global temperature and salinity data sets over several years is a unique opportunity to better characterize the statistics of ocean mesoscale variability at global scale. Although Argo does not resolve mesoscale variability due to its $3^{\circ} \times 3^{\circ}$ spatial sampling, it is very well suited to estimate its main statistical characteristics. Guinehut et al. (2012) derived, for example, statistical relationships between surface and subsurface fields to infer the 3D mesoscale $T$ and $S$ fields from altimetry and sea surface temperature (SST) and Argo observations. We focus here on the spatial scales of temperature and salinity variations. Over several years and in given region, there are many nearly simultaneous pairs of floats with different separation 
distances allowing an estimation of such scales. These estimations are important to better characterize and understand ocean dynamics and to improve quality control, mapping or data assimilation schemes (e.g., Gaillard et al., 2009; Roemmich and Gilson, 2009). They are also essential to refine the sampling requirements for the Argo global array as an optimal sampling should reflect the actual spatial scales (and timescales) of ocean variability.

The paper is organized as follows. Data and methods are presented in Sect. 2. The capability of Argo sampling to estimate spatial correlation scales is analyzed with simulated data in Sect. 3. Section 4 provides a global calculation of spatial scales and discusses the main results. Conclusions and perspectives are given in Sect. 5 .

\section{Data sets and methods}

We used Argo observations from 2005 to 2013 as obtained from the Coriolis data center. Data from 2005 to 2012 are delayed-mode quality-controlled data from the CORA database (Cabanes et al., 2013). Data from 2013 are nearreal-time data from the Coriolis Argo Global Data Assembly Center (one of the two Argo GDACs). An additional quality control with regional climatology checks was applied to these near-real-time data sets.

After several tests (see discussion in Sect. 3), correlation scales were calculated over several large-scale areas to provide a sufficient number of pairs of observations at different zonal and meridional distances. Correlations were computed both for temperature and salinity and for the surface down to $1300 \mathrm{~m}$. The following steps are used for the calculation:

1. The Levitus 2009 seasonal climatology is removed from Argo profile observations.

2. All temperature and salinity Argo data (from 2005 to 2013 ) within a given box (e.g., $20^{\circ}$ latitude $\times 20^{\circ}$ longitude up to $20^{\circ}$ latitude $\times 100^{\circ}$ longitude) are gathered, and a large-scale $\left(4^{\circ} \times 4^{\circ}\right)$ seasonal mean of observations is computed and removed from the observations. This allows removing possible biases in the climatology. Data are then stored in weekly files.

3. The covariance for a given zonal $(\mathrm{d} x)$ and meridional (dy) distance is then calculated as

$$
\begin{aligned}
& \operatorname{Cov}(\mathrm{d} x, \mathrm{~d} y)=\operatorname{Var}-0.5 \gamma(\mathrm{d} x, \mathrm{~d} y), \\
& \begin{aligned}
\gamma(\mathrm{d} x, \mathrm{~d} y) & =1 / N \sum_{\text {all weeks }} \sum_{i j}\left(z^{\prime}\left(x_{i}, y_{i}, t_{i}\right)\right. \\
& \left.-z^{\prime}\left(x_{j}, y_{j}, t_{j}\right)\right)^{2}
\end{aligned}
\end{aligned}
$$

where var is the variance, $\gamma$ is the variogram and $z^{\prime}$ is the anomaly of temperature or salinity at a given depth and $N$ is the number of pairs of Argo profiles whose zonal $\left(x_{i}-x_{j}\right)$ and meridional $\left(y_{i}-y_{j}\right)$ distances are comprised between $\mathrm{d} x \pm 12.5 \mathrm{~km}$ and $\mathrm{d} y \pm 12.5 \mathrm{~km}$ and whose time separations are comprised within \pm 3.5 days. The calculation is done with a spatial zonal and meridional resolution of $25 \mathrm{~km}$. Note that covariances were derived from a variogram calculation to reduce sensitivity of results to unknown mean fields. Since we remove large-scale fields (see point 2 above) prior to the calculation, this only has a minor impact on the calculation.

4. Covariances are then normalized by the variance to get correlation values:

$\operatorname{Cor}(\mathrm{d} x, \mathrm{~d} y)=\operatorname{Cov}(\mathrm{d} x, \mathrm{~d} y) / \operatorname{Cov}(0,0)$.

5. The formal error variance on the correlation, noted $\operatorname{var}_{\mathrm{e}}(\mathrm{d} x, \mathrm{~d} y)$ here, is then derived following the Isserlis theorem (Bendat and Piersol, 1986) and expressed as

$$
\begin{aligned}
\operatorname{var}_{\mathrm{e}}(\mathrm{d} x, \mathrm{~d} y) & =1 / N^{2} \sum_{\text {all weeks }} \sum_{i j} \operatorname{Cor}\left(\mathrm{d} x_{i j}, \mathrm{~d} y_{i j}\right)^{2} \\
& +\operatorname{Cor}\left(\mathrm{d} x+\mathrm{d} x_{i j}, \mathrm{~d} y+\mathrm{d} y_{i j}\right) \\
& \cdot \operatorname{Cor}\left(\mathrm{d} x-\mathrm{d} x_{i j}, \mathrm{~d} y-\mathrm{d} y_{i j}\right) .
\end{aligned}
$$

$\mathrm{d} x_{i j}$ and $\mathrm{d} y_{i j}$ are the zonal and meridional distances between Argo profile $i$ and Argo profile $j$. In practice this calculation is done in an iterative way after an analytical model (see below) is fitted to covariance observations. Note that if we assume that the $N$ pairs of observations provide uncorrelated estimations of the covariance for a given $\mathrm{d} x$ and $\mathrm{d} y$ lag (which is the case if $\mathrm{d} x_{i j} \gg \mathrm{d} x$ or $\mathrm{d} y_{i j} \gg \mathrm{d} y$ ), the formal error variance on the correlation is simply equal to the following expression:

$\operatorname{var}_{\mathrm{e}}(\mathrm{d} x, \mathrm{~d} y)=1 / N[1+\operatorname{cor}(\mathrm{d} x, \mathrm{~d} y)]$.

It shows that RMSEs (root-mean-square errors) on correlations vary as $1 / \sqrt{ } N$ (e.g., 100 observation pairs should lead to an error of 0.1 to 0.2 ).

6. An analytical correlation model is then fitted to the discrete correlation estimations through a non-linear weighted least-square curve fitting method based on the Levenberg-Marquardt algorithm. Formal errors (see point 5 above) are taken into account in the adjustment (weights). The correlation model follows the covariance model proposed by Arhan and Colin de Verdière (1985).

$$
\begin{aligned}
\operatorname{Cor}(\mathrm{d} x, \mathrm{~d} y)= & (1 / 1+E)\left[1+a r+(a r)^{2} / 6-(a r)^{3} / 6\right] \\
& \exp (-a r) \text { if } r \neq 0 \\
\operatorname{Cor}(\mathrm{d} x, \mathrm{~d} y)= & 1 \text { if } r=0, \\
r= & {\left[\left(\mathrm{d} x / L_{x}\right)^{2}+\left(\mathrm{d} y / L_{y}\right)^{2}\right]^{1 / 2} . }
\end{aligned}
$$

$L_{x}$ and $L_{y}$ are the zonal and meridional scales (zonal and meridional zero crossings of the correlation function). $E$ is the noise variance that represents both measurement and representativity errors. $a$ is a constant 

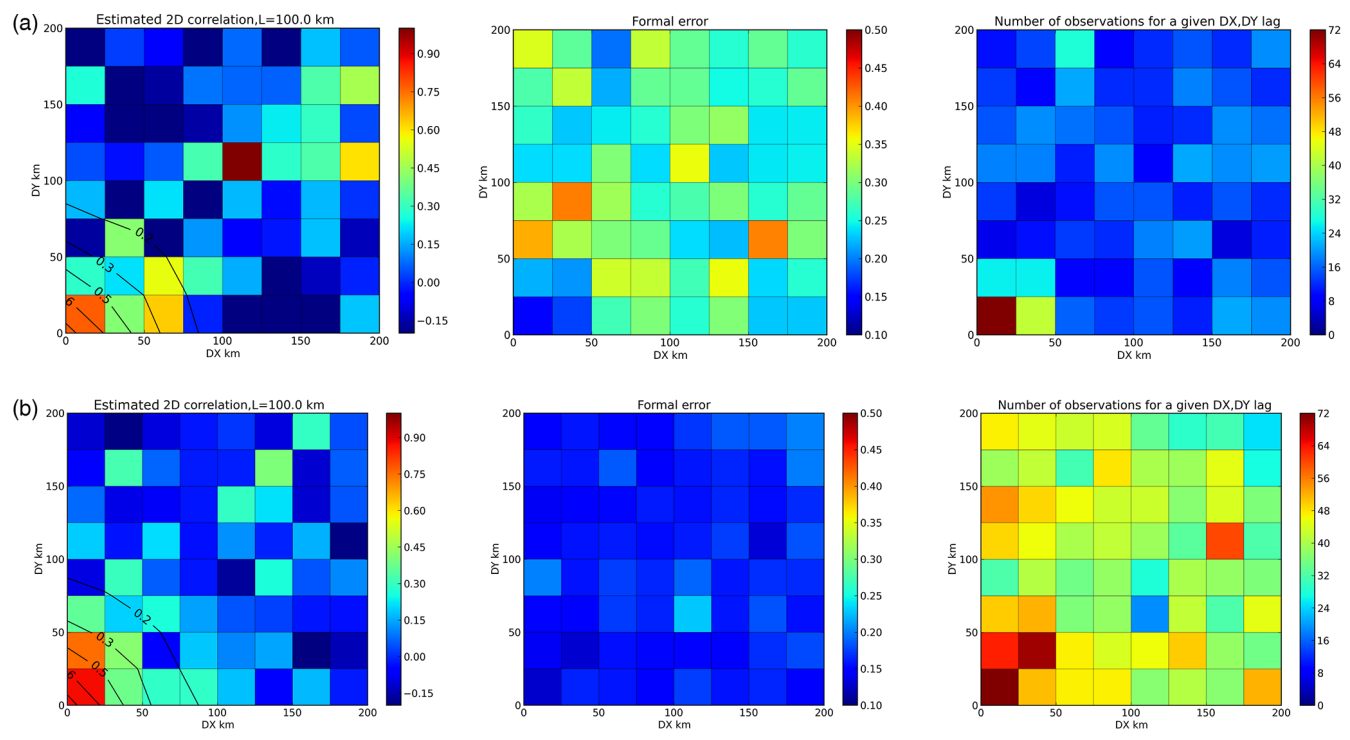

Figure 1. (a) Estimated 2-D covariance fields for the $L=100 \mathrm{~km}$ simulation for the 2005 Argo sampling (left), associated formal errors (middle) and number of observation pairs (right). (b) Estimated 2-D covariance fields for the $L=100 \mathrm{~km}$ simulation for the $2013 \mathrm{Argo}$ sampling (left), associated formal errors (middle) and number of observation pairs (right).
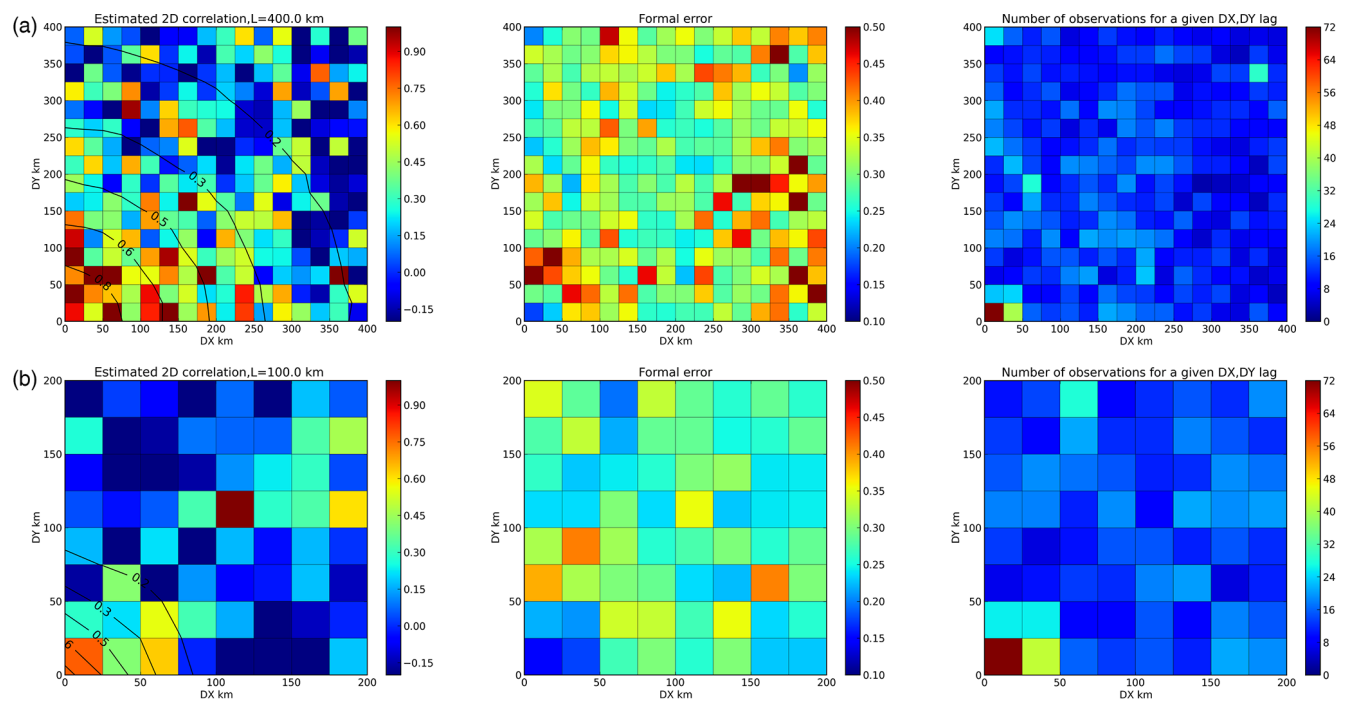

Figure 2. (a) Estimated 2-D covariance fields for the $L=400 \mathrm{~km}$ simulation for the 2005 Argo sampling (left), associated formal errors (middle) and number of observation pairs (right). (b) Estimated 2-D covariance fields for the $L=400 \mathrm{~km}$ simulation for the 2013 Argo sampling (left), associated formal errors (middle) and number of observation pairs (right). Black isolines (left) correspond to the adjusted covariance model.

equal to 3.337 calculated so that $\left[1+a+a^{2} / 6-a^{3} / 6\right]=$ 0 , i.e., Cor $(\mathrm{d} x, \mathrm{~d} y)=0$ when $r$ is equal to 1 . This ensures that $L_{x}$ and $L_{y}$ scales correspond to zero crossing of correlation scales. The fitting procedure provides estimation of $L_{x}$ and $L_{y}$ and of their formal errors. Another calculation of error ("standard fitting errors") is also carried out by using a least-square fitting with unit weights to characterize the consistency of correlation estimations with our correlation model.

\section{Sensitivity of results to sampling: a simulation study}

To analyze the sensitivity of results to Argo sampling, a simulation study was performed. The main objective is to test the impact of realistic Argo sampling by using actual Argo float positions in 2005 and 2013 in the North Pacific. Over a $20^{\circ} \times 20^{\circ}$ box, 1600 Argo profiles were available in 2005 and about 2700 for 2013 . A nominal $3^{\circ} \times 3^{\circ}$ Argo sampling would yield about 1800 profiles per year for a $20^{\circ} \times 20^{\circ}$ box; 


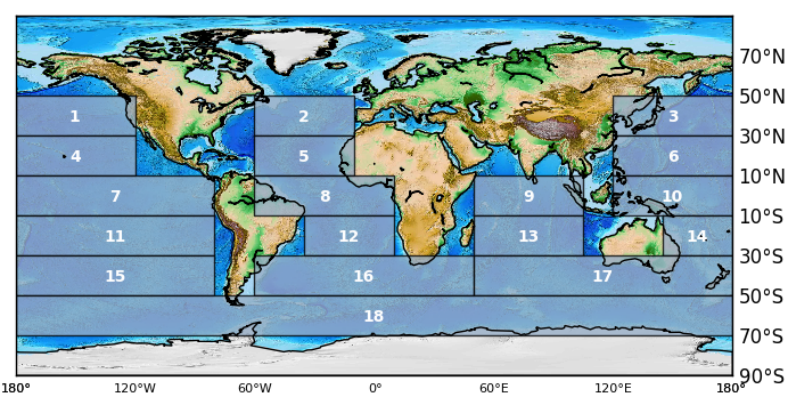

Figure 3. Large-scale areas where temperature and salinity spatial correlations were calculated.
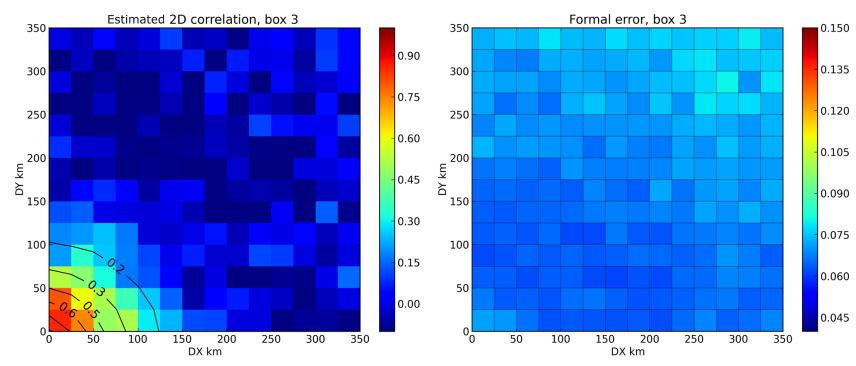

Figure 4. 2-D covariance calculated in a $20^{\circ} \times 60^{\circ}$ area (box number 3 ) in the North Pacific Ocean (left) and associated formal error (right) for temperature at $200 \mathrm{~m}$. Black isolines (left) correspond to the adjusted covariance model.

2005 is thus close to a nominal Argo sampling and 2013 corresponds to an improved Argo sampling.

Table 1. Simulation of the impact of Argo sampling on the estimation of correlation functions.

\begin{tabular}{lll}
\hline Simulation type & Estimated $L$ & $\begin{array}{l}\text { Associated } \\
\text { error }(1 \sigma)\end{array}$ \\
\hline$L=100 \mathrm{~km}-2005$ sampling & $70 \mathrm{~km}$ & $20 \mathrm{~km}$ \\
$L=100 \mathrm{~km}-2013$ sampling & $89 \mathrm{~km}$ & $11 \mathrm{~km}$ \\
$L=400 \mathrm{~km}-2005$ sampling & $372 \mathrm{~km}$ & $30 \mathrm{~km}$ \\
$L=400 \mathrm{~km}-2013$ sampling & $418 \mathrm{~km}$ & $20 \mathrm{~km}$ \\
\hline
\end{tabular}

We generated 52 weekly (i.e., 1 year) simulated temperature 2-D fields on a $20^{\circ} \times 20^{\circ}$ grid that follows the Arhan and Colin de Verdière (1985) covariance model. The 2-D temperature fields were then sampled at the float positions in 2005 and 2013, and an observation noise of $10 \%$ was added $(E=0.1)$. From these simulated Argo data, we analyzed how well covariance functions can be reconstructed following the method outlined in Sect. 2. The calculations were done both for $L=100 \mathrm{~km}$ and $L=400 \mathrm{~km}$ (isotropic field with $L=L_{x}=L_{y}$ ). Figure 1a and b show the estimated 2-D correlation fields for the $L=100 \mathrm{~km}$ simulation for the 2005 and 2013 sampling and the associated formal error. Figure $2 \mathrm{a}$ and $\mathrm{b}$ show the same results but for the $L=400 \mathrm{~km}$
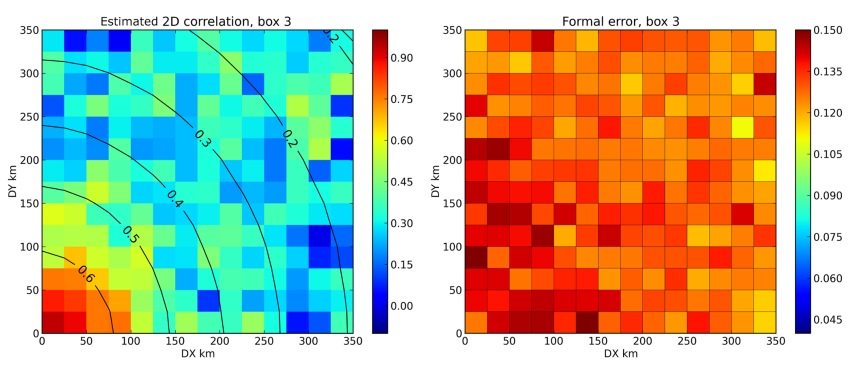

Figure 5. 2-D covariance calculated in a $20^{\circ} \times 60^{\circ}$ area (box number 3 ) in the North Pacific Ocean (left) and associated formal error (right) for temperature at $1000 \mathrm{~m}$. Black isolines (left) correspond to the adjusted covariance model.
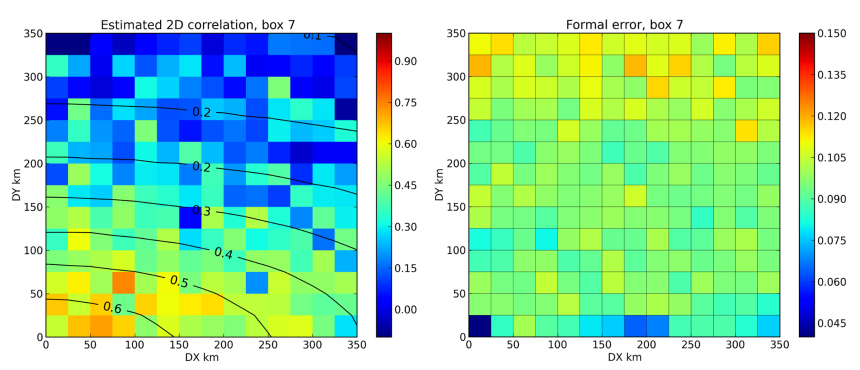

Figure 6. 2 -D covariance calculated in a $100^{\circ} \times 20^{\circ}$ area (box number 7) in the equatorial Pacific Ocean (left) and associated formal error (right) for temperature at $200 \mathrm{~m}$. Black isolines correspond to the adjusted covariance model.

simulations. Table 1 summarizes the results for correlation scale and associated error estimations.

Results show that the estimations of correlation functions are highly sensitive to the Argo sampling. The typical error for a covariance or correlation value is about $0.25-0.4$ for the 2005 sampling and $0.15-0.25$ for the 2013 sampling over a 1 -year time period. Correlation scales (assuming an a priori knowledge of the covariance function shape) can be determined with an accuracy of about 20 to $30 \mathrm{~km}$ for 2005 and 10 to $20 \mathrm{~km}$ for 2013 . These results are obviously dependent on the number of observation pairs available for a given spatial $\mathrm{d} x$ and $\mathrm{d} y$ lag. Correlation errors are also larger for the $400 \mathrm{~km}$ simulation because there are less independent observations of correlation.

These results show that 1 year of Argo observations over a $20^{\circ} \times 20^{\circ}$ box does not allow estimating precise enough correlation functions. When the sampling is improved as in 2013 , results are, however, significantly improved. These results can easily be extrapolated to longer time series (and/or larger boxes) as correlation RMSEs are proportional to the number of observation pairs at a given spatial lag (see equation in Sect. 2). RMSEs for a 4-year time period will thus be divided by a factor of 2 . In that case, we expect errors on correlation of about 0.1 to 0.2 and an error on correlation scales below $10 \mathrm{~km}$. 

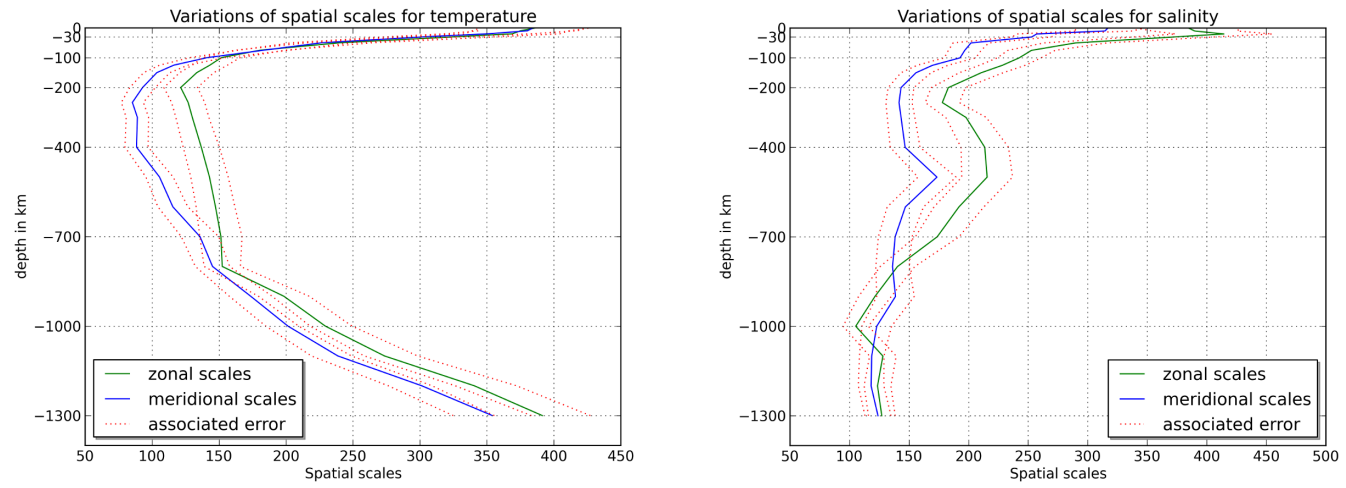

Figure 7. Variations of zonal and meridional spatial scales for temperature (left) and salinity (right) according to depth for box 18 (highlatitude Southern Hemisphere). Dotted lines represent standard fitting errors.
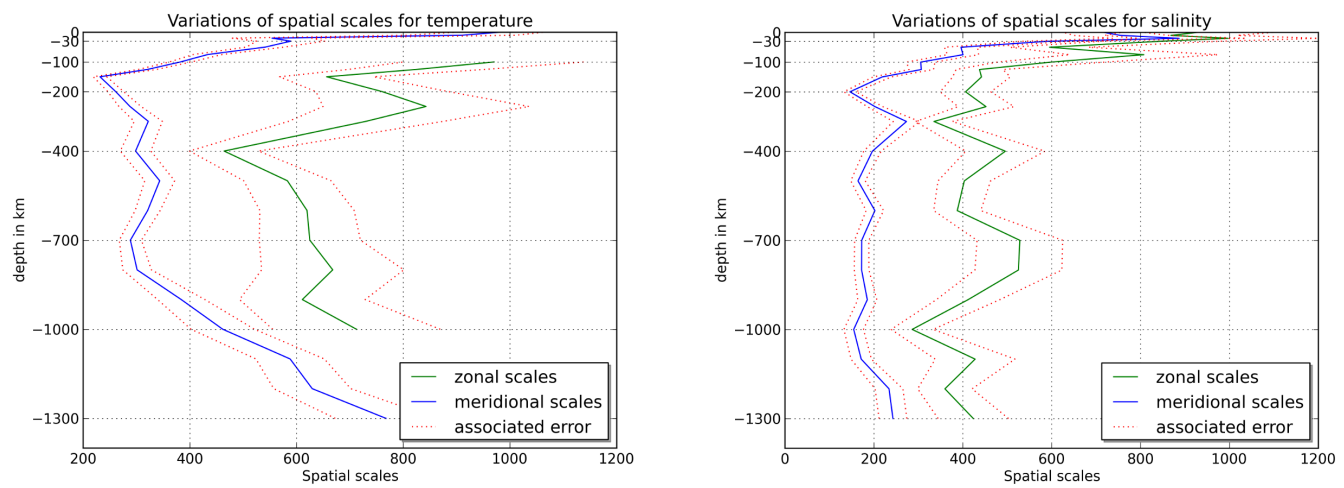

Figure 8. Variations of zonal and meridional spatial scales for temperature (left) and salinity (right) according to depth for box 9 (equatorial Indian and Pacific). Dotted lines represent standard fitting errors.

\section{Results and discussion}

A preliminary calculation of spatial scales ( $L_{x}$ and $L_{y}$ which are also zero crossing of correlation functions) was carried out over several large areas (Fig. 3). Calculations were done both for temperature and salinity and all depths from the surface down to $1300 \mathrm{~m}$.

Results for one box (box 3) in the North Pacific are shown in Figs. 4 and 5 for temperature at two different depths (200 and $1000 \mathrm{~m}$ ). In that box, correlations are well estimated with a typical error below 0.1 due a large number of observation pairs $N$ for a given zonal and meridional spatial lag ( $N$ comprised between 200 and 400). The estimated zonal and meridional correlation scales are 130 and $110 \mathrm{~km}$ respectively. This is consistent with results derived from altimeter data analysis in midlatitude regions (e.g., Kuragano and Kamachi, 2000; Jacobs et al., 2001; Le Traon et al., 2003). Correlation scales are significantly larger at $1000 \mathrm{~m}$ (Fig. 5), and $L_{x}$ and $L_{y}$ are estimated to 185 and $160 \mathrm{~km}$ respectively. Salinity scales (not shown) are very close to temperature ones although the estimation is slightly noisier.

Zonal and meridional spatial scales vary as expected with latitudes. Compared to midlatitude regions, scales are much larger in the tropical and equatorial regions. Figure 6 shows, for example, the correlation function for temperature at $200 \mathrm{~m}$ in the whole equatorial Pacific. Zonal and meridional scales are estimated to about 900 and $350 \mathrm{~km}$. The zonal scales are smaller than those derived from TAO observations and larger than those derived from altimeter data (e.g., Kessler et al., 1996; Jacobs et al., 2001). This may be due to both the techniques used to compute scales (e.g., removing of large-scale signals before computing altimeter spatial scales) and the sparse spatial sampling of TAO observations. As expected and well observed from altimetry and in situ observations, there is a strong anisotropy with zonal scales 2-3 times larger than meridional scales. It is interesting to note that, compared to the Pacific Ocean, smaller zonal scales are observed in the Indian (box 9 - zonal scale of $780 \mathrm{~km}$ at $200 \mathrm{~m}$ for temperature) and Atlantic (box 8 - zonal scale of $360 \mathrm{~km}$ at $200 \mathrm{~m}$ for temperature) tropical-equatorial oceans.

They are also interesting variations of scales according to depth. Figures 7, 8 and 9 show the vertical distribution of scales both for temperature and salinity for several areas (boxes 2, 9 and 18). At the surface or in the mixed layer, scales are much larger because they reflect large-scale atmospheric forcing (heat flux, evaporation and precipitation). 

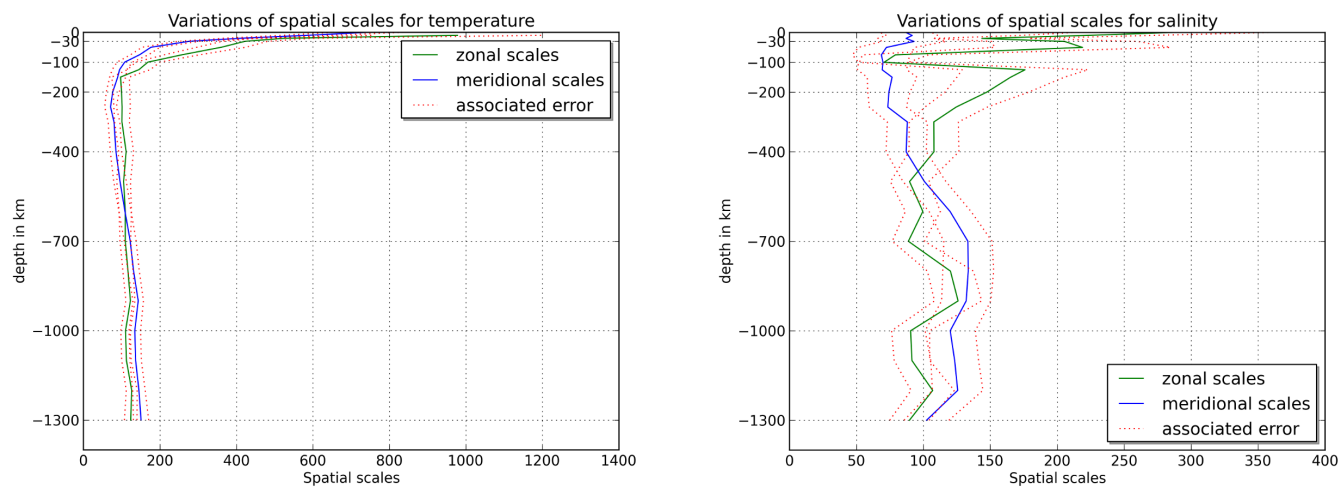

Figure 9. Variations of zonal and meridional spatial scales for temperature (left) and salinity (right) according to depth for box 2 (midlatitude North Atlantic). Dotted lines represent standard fitting errors.

Note, however, that a mean seasonal cycle is removed prior to the calculation. Below the mixed layer, scales are more representative of mesoscale dynamics and are consistent with scales derived from satellite altimetry. There is a general tendency (not systematic though) for an increase of temperature scales at depths larger than $800-1000 \mathrm{~m}$ although the correlation functions are noisier there because of lower signals. This may reflect a smaller influence of mesoscale variability at deeper depths, but this should be investigated further.

There are significant differences between salinity and temperature scales (see Figs. 7, 8 and 9). At the surface and in the mixed layer where we observe large spatial scales, differences may reflect differences in scales between $E-P$ (in particular precipitation) and heat flux forcing. At mid-depth and depending on regions, differences may reflect the different dynamical nature of temperature and salinity signals. It is interesting to note, in particular, that the increase of scales for depths deeper than $800-1000 \mathrm{~m}$ for boxes 9 and 18 is not observed for salinity as it is for temperature. In many ocean regions (in particular tropics and subtropics) and for the deep ocean, temperature variations are more important than salinity in changing density. Temperature variations are thus more representative of ocean dynamics, and salinity is more acting as a tracer of circulation. In 2-D ocean turbulence, a tracer would exhibit smaller scales than density (or temperature) with a less steep wavenumber spectrum (e.g., Vallis, 2006). Although we tend to observe smaller salinity scales, this should be analyzed further and globally.

A similar calculation was done by Resnyanskii et al. (2010) but with a more limited Argo data set (2005-2007). Our results are in a qualitative agreement with theirs although they found larger scales. This may be due to the differences in data sets but also to differences in the way spatial scales were computed. They did not remove, in particular, biases in the Levitus climatology.

\section{Conclusions and perspectives}

This study was a first attempt to estimate spatial scales of temperature and salinity at different depths from the Argo global ocean observing system. A careful error analysis was carried out, and it shows that several years of Argo observations are required for a precise enough (error on correlation below 0.1 to 0.2 ) estimation of correlation functions over $20^{\circ} \times 20^{\circ}$ boxes. Correlation functions and associated zonal and meridional spatial scales were then calculated over several large areas over the global ocean. Scales vary from 350 to $900 \mathrm{~km}$ in the equatorial regions down to less than $100 \mathrm{~km}$ at high latitudes. Zonal and meridional scales are similar except in the Pacific and Indian tropical-equatorial regions where zonal scales are much larger (by a factor of 2 to 3) than meridional scales. These results are consistent with previous studies based on sparse in situ observations or satellite altimetry, but they allow for the first time a global characterization, an analysis of differences of scales between temperature and salinity and the variations of scales according to depths. As the Argo array develops, more precise and/or higher-resolution estimations can be derived. We plan to extend soon these analyses to time and space-time correlation estimations. Similar calculations will also be applied to characterize global eddy-resolving model errors, i.e., instead of analyzing Argo observations minus climatology analyzing Argo observations minus a model guess. This is essential to improve data assimilation systems.

Acknowledgements. These data were collected and made freely available by the International Argo Program and the national programs that contribute to it (http://www.argo.ucsd.edu and http://argo.jcommops.org). The Argo program is part of the Global Ocean Observing System. The study was partly carried out as part of the FP7 E-AIMS project (grant agreement no. 312642).

Edited by: A. Crise 


\section{References}

Arhan, M. and Colin De Verdière, A.: Dynamics of Eddy Motions in the Eastern North Atlantic, J. Phys. Oceanogr., 15, 153-170, 1985.

Bendat, J. S. and Piersol, A. G.: Random data analysis and measurement procedures, J. J. Wiley-Interscience Publication John Wiley and Sons, New York, 566 pp., 1986.

Cabanes, C., Grouazel, A., von Schuckmann, K., Hamon, M., Turpin, V., Coatanoan, C., Paris, F., Guinehut, S., Boone, C., Ferry, N., de Boyer Montégut, C., Carval, T., Reverdin, G., Pouliquen, S., and Le Traon, P.-Y.: The CORA dataset: validation and diagnostics of in-situ ocean temperature and salinity measurements, Ocean Sci., 9, 1-18, doi:10.5194/os-9-1-2013, 2013.

Dong, C., McWilliams, J. C., Liu, Y., and Chen, D.: Global heat and salt transports by eddy movement, Nat. Commun., 5, doi:10.1038/ncomms4294, 2014.

Durack, P. J., and Wijffels, S. E.: Fifty-year trends in global ocean salinities and their relationship to broad-scale warming, J. Climate, 23, 4342-4362, 2010.

Freeland, H. J., Roemmich, D., Garzoli, S. L, Le Traon, P.-Y., Ravichandran, M., Riser, S., Thierry, V., Wijffels, S., Belbeoch, M., Gould, J. , Grant, F., Ignazewski, M., King, B., Klein, B., Mork, K. A., Owens, B., Pouliquen, S., Sterl, A., Suga, T., Suk, M.-S., Sutton, P., Troisi, A., Velez-Belchi, P. J., and Xu, J.: Argo - A Decade of Progress. Proceedings of OceanObs'09, in: Sustained Ocean Observations and Information for Society (Vol. 2), edited by: Hall, J., Harrison D. E., and Stammer, D., Venice, Italy, 21-25 September 2009, ESA Publication WPP-306, 2010.

Gaillard, F., Autret, E., Thierry, V., Galaup, P., Coatanoan, C., and Loubrieu, T.: Quality control of large argo datasets, J. Atmos. Ocean. Tech., 26, 337-351, doi:10.1175/2008JTECHO552.1, 2009.

Guinehut, S., Dhomps, A.-L., Larnicol, G., and Le Traon, P.Y.: High resolution 3-D temperature and salinity fields derived from in situ and satellite observations, Ocean Sci., 8, 845-857, doi:10.5194/os-8-845-2012, 2012.

Jacobs, G. A., Barron, C. N., and Rhodes, R. C.: Mesoscale characteristics, J. Geophys. Res., 106, 19581-19595, doi:10.1029/2000JC000669, 2001.

Kessler, W. S., Spillane, M. C., McPhaden, M. J., and Harrison, D. E: Scales of Variability in the Equatorial Pacific Inferred form Tropical Atmosphere-Ocean Buoy Array, J. Climate, 9, 2999-3024, doi:10.1175/15200442(1996)009<2999:SOVITE>2.0.CO;2, 1996.
Kuragano, T. and Kamachi, M.: Global statistical spacetime scales of oceanic variability estimated from the TOPEX/POSEIDON altimeter data, J. Geophys. Res., 105, 955-974, doi:10.1029/1999JC900247, 2000.

Le Traon, P. Y., Faugère, Y., Hernandez, F., Dorandeu, J, Mertz, F, and Ablain, M.: Can we merge GEOSAT Follow-On with TOPEX/Poseidon and ERS-2 for an improved description of the ocean circulation?, J. Atmos. Ocean. Tech., 20, 889-895, doi:10.1175/1520-0426(2003)020<0889:CWMGFW>2.0.CO;2, 2003.

Le Traon, P. Y.: From satellite altimetry to Argo and operational oceanography: three revolutions in oceanography, Ocean Sci., 9, 901-915, doi:10.5194/os-9-901-2013, 2013.

Oke, P. R., Balmaseda, M. A., Benkiran, M., Cummings, J. A., Fujii, Y., Guinehut, S., Larnicol, G., Le Traon, P.-Y., Martin, M. J., and Dombrowsky, E.: Observing System Evaluations using GODAE systems, Oceanography, 22, 144-153, 2009.

Resnyanskii Y. D., Tsyrulnikov, M. D., Strukov, B. S., and Zelenko, A. A.: Statistical structure of spatial variability of the ocean thermohaline fields from Argo profiling data, 2005-2007, Oceanology, 50, 149-165, doi:10.1134/S0001437010020013, 2010.

Roemmich, D., Gilson, J., Davis, R., Sutton, P., Wijffels, S., and Riser, S.: Decadal spinup of the South Pacific subtropical gyre, J. Phys. Oceanogr., 37, 162-173, doi:10.1175/JPO3004.1, 2007.

Roemmich, D. and Gilson, J.: The 2004-2008 mean and annual cycle of temperature, salinity, and steric height in the global ocean from the Argo Program, Prog. Oceanogr., 82, 81-100, doi:10.1016/j.pocean.2009.03.004, 2009.

Roemmich, D. and the Argo Steering Team: Argo: the challenge of continuing 10 years of progress, Oceanography, 22, 46-55, doi:10.5670/oceanog.2009.65, 2009.

Vallis, G. K.: Atmospheric and Oceanic Fluid Dynamics, Cambridge University Press, 745 pp., 2006.

von Schuckmann, K. and Le Traon, P.-Y.: How well can we derive Global Ocean Indicators from Argo data?, Ocean Sci., 7, 783791, doi:10.5194/os-7-783-2011, 2011. 